\title{
Fine needle aspiration biopsy in orbital tumours
}

\author{
Jan W M Tijl, Leo Koornneef
}

\begin{abstract}
Fine needle aspiration biopsy (FNAB) was performed in 46 patients with an orbital mass. Positive cytological identification was made in 43 biopsy specimens. In 26 cases with histopathological control the accuracy was $81 \%$. In experienced hands FNAB is safe and appears to be a valuable tool in establishing a diagnosis of malignancy in orbital tumours.
\end{abstract}

Fine needle aspiration biopsy (FNAB) has been used in the diagnosis of neoplasms of various organs such as thyroid, pancreas, lung, abdomen, or breast. ${ }^{1-4}$ Schyberg ${ }^{5}$ was the first to describe its use in orbital tumours. Ideally FNAB should establish the diagnosis of a malignant unresectable orbital neoplasm, to eliminate or plan the need for surgical intervention.

In this study the value of FNAB in the diagnosis of orbital tumours is evaluated, and its place in the management of orbital tumours will be discussed.

\section{Material and methods}

Between 1984 and 1990 FNAB was performed in 46 of the patients referred to the Orbital Centre with an orbital mass. The technique has been described previously in more detail. ${ }^{6} \mathrm{~A} 23$ gauge needle attached to a $20 \mathrm{ml}$ disposable syringe held in a pistol grip (Cameco, Sweden) is used. After thorough cleaning of the skin the area above the tumour is firmly held with one hand and the needle is inserted through the skin into the lesion. No local anaesthesia is required. When the needle enters the tumour, the operator retracts the plunger, obtaining a negative pressure in the system. To aspirate sufficient material the needle is moved back and forth into the lesion while the vacuum is maintained. Then the plunger is released, equalising the pressure in the system, and the needle is withdrawn from the mass and slides are prepared. The accuracy of the FNABs with histopathological control was calculated.

\section{Results}

The age of the patients at presentation varied from 20 to 89 years (median $60 \mathrm{yr}$ ). There were 29 women and 17 men. The presenting symptoms were swelling in 14, ptosis in 12, pain in 11 , proptosis in 11 , diplopia in 10 , visual acuity decrease in three, and epiphora in two patients. The site of the tumours was superotemporal in two, on the eyelid in 15 , superonasal in two, retrobulbar in one, and in the lacrimal sac in one. The extent of the tumour was established by computed tomography (CT) in all cases. Biopsy was performed on retrobulbar tumour with CT guidance. The cytological diagnoses are listed in Table 1. Three biopsies yielded insufficient material. Eighteen of the aspirates were diagnosed as benign whereas 25 were diagnosed as malignant. Histopathological control was available in 26 cases (57\%). In 21 cases histopathology confirmed the cytological diagnosis. In five cases the cytological diagnosis did not correspond to the histopathology. The cytological diagnosis was pseudolymphoma in these five cases, whereas histopathological control showed a non-Hodgkin's lymphoma in three cases and a liposarcoma in two cases. This yields an accuracy of $81 \%$ in the group with histopathological control.

\section{Discussion}

A major area of concern in FNAB is sampling error. While the accuracy is high, false positive reports which may lead to an operation as the result of a faulty diagnosis are almost nonexistent. In the group with histopathological control the accuracy was $81 \%$. However, in five cases cytological diagnosis did not show a malignancy whereas histopathological control did, so we still have to regard non-malignant results of an FNAB with suspicion.

In other studies of FNAB of the orbit the accuracy varied from 47 to $100 \% .^{7-12}$ But not all biopsies had histopathological control. Krohel et al found only $47 \%$ accuracy in FNAB under direct visualisation. ${ }^{7}$ In their study there was a routine pathological examination after surgery in all cases, but $50 \%$ of the lesions did not lend themselves to identification by FNAB.

The indication for FNAB in all patients was to establish or exclude a diagnosis of malignancy, which is mandatory in deciding between surgery and observation. In operable cases surgical treatment may be systematically planned at an early stage; in inoperable cases it may suffice to establish the diagnosis. ${ }^{1}$ It is a simple and safe diagnostic method ${ }^{113-16}$ and provides the necessary information with minimal or no alteration in the natural behaviour of the tumour. ${ }^{18}$ FNAB is usually less painful than a venepuncture, so there is no need for local anaesthesia. In this way the distortion of the local anatomy can be minimised. ${ }^{17}$ Needle tract seeding described after punctures in other places ${ }^{18-21}$ was not observed.

Table Cytological diagnosis after $F N A B(n=46)$

\begin{tabular}{ll}
\hline Pseudolymphoma & $9(9)^{\star}$ \\
Non-Hodgkin's lymphoma & $8(2)$ \\
Adenocarcinoma & $7(2)$ \\
Non-specific inflammation & $6(4)$ \\
Squamous cell carcinoma & $4(2)$ \\
Pleomorphic adenoma & $4(4)$ \\
Adencystic carcinoma & $1(1)$ \\
Dermoid cyst & $1(1)$ \\
Neuroblastoma & 1 \\
Old haematoma & $1(1)$ \\
Eosinophilic granuloma & 1 \\
Inadequate specimen & 3
\end{tabular}

${ }^{\star}$ Histopathological control in parentheses 
When the tumour is located in a palpable site, the biopsy is easier than when it is situated deep in the orbit. Kennerdell $e t a l^{13}$ advocate that fine needle aspiration should not be used for lesions that are anterior to the orbital septum, but prefer incisional or excisional biopsy techniques for these lesions. We consider FNAB easy and less invasive than an incisional biopsy. Since doubtful non-malignant results can easily be verified, our first choice will be FNAB in these preseptal lesions.

The CT scan is an indispensable tool in locating a process in the orbit. ${ }^{16}$ If the mass is inside the muscle cone adjacent to the optic nerve, ultrasound usually provides helpful guidance. Orbital apex tumours and optic nerve lesions may be reached with CT guidance. . $^{13} 15-1722-24$ Without the help of CT or ultrasound FNAB should be restricted to preseptal and parabulbar areas to prevent complications. ${ }^{22}$

Better results are obtained when all the aspirations are performed by one clinician who is proficient in the technique. ${ }^{25}$ The specimen should be interpreted by one person both familiar with the identification of cells in smears and experienced in orbital pathology. If any of the team members are not available or a lack of enthusiasm for the technique predominates, it is doomed to failure. ${ }^{13}$

Because FNAB acquires a small volume of tissue at the tip of a needle, representative tissue may not be obtained and a sampling error is introduced. One may sample the inflammatory response at the periphery of a neoplasm rather than the neoplasm itself, resulting in a misdiagnosis. ${ }^{1326}$ Wegener's granulomatosis is one of the diseases that can easily be missed owing to its inflammatory appearance. ${ }^{27}$ Moreover in tumours of fibrous consistency and those located in the orbital apex, or in lymphocytic lesions, FNAB is less reliable..$^{28}$

Considering the good results that have been reported, together with our own, we consider a FNAB to be reliable if the cytology points in the direction of malignancy. In contrast, a nonmalignant cytological diagnosis should not be considered an unequivocal proof of absence of malignant disease. Lesions whose aspirates contain non-diagnostic material and whose clinical appraisals are in disagreement with the cytological findings (in our series the pseudolymphomas) should always be subjected to biopsy for histopathological examination. ${ }^{29}$

In conclusion, FNAB is a rapid and minimally invasive diagnostic technique that shortens time in hospital and reduces the costs of health care.
We thank Dr J Bras for carrying out the FNABs and all the cytology and histology.

1 Einhorn J, Franzén S. Thin-needle biopsy in the diagnosis of thyroid disease. Acta Radiol (Diagn) (Stockh) 1962; 58: 32136.

2 Schour L, Chu EW. Fine needle aspiration in the management of patients with neoplastic disease. Acta Cytol (Baltimore) 1974; 18: 472-6.

3 Zadjela A, Ghossein NA, Pilleron JP, Ennuyer A. The value of aspiration cytology in the diagnosis of breast cancer: experience at the Foundation Curie. Cancer 1975; 35: 499506.

4 Kline TS, Neal HS. Needle aspiration biopsy. A critical appraisal. Eight years and 3267 specimens later. $\mathscr{f} A M A$ appraisal. Eight

5 Schyberg E. Fine needle biopsy of orbital tumours. Acta Ophthalmol (Kbh) 1975; suppl 125: 11.

6 Midena E, Segato T, Piermarocchi S, Boccato P. Fine needle aspiration biopsy in ophthalmology. Surv Ophthalmol 1985; 29: 410-22.

7 Krohel GB, Tobin DR, Chavis RM. Inaccuracy of fine needle aspiration biopsy. Ophthalmology 1985; 92: 666-70.

8 Heerde $v$ P, Peterse JL. Fine needle aspiration of the orbit. Orbit 1985; 4: 217-20.

9 Kennerdell JS, Slamovits TL, Dekker A, Johnson BL. Orbital fine-needle aspiration biopsy. Am $\mathcal{F}$ Ophthalmol 1985; 99: $547-51$

10 Westman-Naeser S, Naeser P. Tumours of the orbit diagnosed by fine needle biopsy. Acta Ophthalmol (Kbh) 1978; 56: 969-

11 Tarkanen A, Koivuniemi A, Liesmaa M, Merenmies L. Fineneedle aspiration biopsy in the diagnosis of orbital tumours. Grafes Arch Clin Exp Ophthalmol 1982; 219: 165-70.

12 Zadjela A, Vielh P, Schlienger P, Haye C. Fine-needle cytology of 292 palpable orbital and eyelid tumors. Am 7 Clin Pathol 1990; 93: 100-4.

13 Kennerdell JS, Dekker A, Johnson BL. Orbital fine needle aspiration biopsy: the results of its use in 50 patients. Neuro Ophthalmol 1980; 1: 117-21.

14 Spoor TC, Kennerdell JS, Dekker A, Johnson BL, Rehkopf P. Orbital fine needle aspiration biopsy with B-scan guidance. Am f Ophthalmol 1980; 89: 274-7.

15 Slamovits TL, Cahill KV, Sibony PA, Dekker A, Johnson BL. Orbital fine-needle aspiration biopsy in patients with cavernous sinus syndrome. $\mathcal{F}$ Neurosurg 1983; 59: 1037-42.

16 Maroon JC, Kennerdell JS. Surgical approaches to the orbit: indications and techniques. $\mathcal{F}$ Neurosurg $1984 ; 60$ : 1226-35.

17 Kennerdell JS, Dubois PJ, Dekker A, Johnson BL. CTguided fine needle aspiration biopsy of orbital optic nerve tumors. Ophthalmology 1980; 87: 491-6.

18 Ferruci JT, Wittenberg J, Margolies MN, Carey RW. Malignant seeding of the tract after thin-needle aspiration biopsy. Radiology 1979; 130: 345-6.

19 Engzell U, Esposti PL, Rubio C, Sigurdson A, Zajicek J. Investigation on tumour spread in connection with aspiration biopsy. Acta Radiol Ther Phys Biol 1971; 10: 385-98.

20 Sinner WN, Zajicek J. Implantation metastasis after percutaneous transthoracic needle aspiration biopsy. Acta Radiol (Diagn) (Stockh) 1976; 17: 473-80

21 Smith FP, Macdonald JS, Schein PS, Ornitz RD. Cutaneous seeding of pancreatic cancer by skinny-needle aspiration biopsy. Arch Intern Med 1980; 140: 855.

22 Dubois PJ, Kennerdell JS, Rosenbaum AE, Dekker A, Johnson BR, Swink CA. Computed tomographic localization for fine needle aspiration biopsy of orbital tumors. Radiology 1979; 131: 149-52.

23 Dresner SC, Kennerdell JS, Dekker A. Fine needle aspiration biopsy of metastatic orbital tumors. Surv Ophthalmol 1983; 27: 397-8.

24 Kincaid MC, Green WR. Diagnostic methods in orbital diseases. Ophthalmology 1984; 91: 719-25.

25 Liu D. Complications of fine needle aspiration biopsy of the orbit. Ophthalmology 1985; 92: 1768-71.

26 Poe RH, Tobin RE. Sensitivity and specificity of needle biopsy in lung malignancy. Am Rev Respir Dis 1980; 122: 725-9.

27 Koornneef L, Melief CJM, Peterse HL, Wilmink JM Wegener's granulomatosis of the orbit. Diagnostic and therapeutic problems. Orbit 1983; 2: 1-10.

28 Kennerdell JS, Slamovits TL, Dekker A, Johnson BL. Orbital fine-needle aspiration biopsy. Am $\mathcal{F}$ Ophthalmol 1985; 99: fine-needle

29 Arora R, Rewari R, Betheria SM. Fine needle aspiration cytology of eyelid tumors. Acta Cytol (Baltimore) 1990; 34 : 227-32. 